\title{
JOSÉ ALAMEDA Y UN SONETO DE FEDERICO GARCÍA LORCA
}

\author{
JOSÉ ALAMEDA AND A SONNET \\ BY FEDERICO GARCÍA LORCA
}

\author{
Ana Coleto Camacho \\ Universidad de Sevilla \\ acoleto1@gmail.com
}

\begin{abstract}
Resumen: El soneto de Federico García Lorca "El poeta pide a su amor que le escriba" arrastró una larga historia desde que fue concebido por el poeta hasta que fue publicado con este título y como parte integrante de la serie de Sonetos del amor oscuro. Este artículo propone aclarar algunas de las incógnitas de esta historia de transmisión textual. Con tal finalidad, el artículo aporta nuevos datos que documentan, por un lado, la procedencia del apógrafo que ha servido de texto base para editar el poema, y, por otro, el papel que ha desempeñado en esta historia José Alameda.

Palabras clave: Federico García Lorca; Carlos Fernández López de Valdemoro (José Alameda); Sonetos del amor oscuro; "El poeta pide a su amor que le escriba"; historia textual.
\end{abstract}

Abstract: A lot of things happened between the time Federico García Lorca wrote his sonnet "El poeta pide a su amor que le escriba" and its eventual publication under this title as part of the sequence of Sonetos del amor oscuro. The purpose of this article is to shed light on some of the unexplained aspects in the transmission of the poem from manuscript to published text. To this end it offers new data concerning the source of one of the transcriptions used to edit the poem, together with information about the part played in this story by José Alameda.

Keywords: Federico García Lorca; Carlos Fernández López de Valdemoro (José Alameda); Sonetos del amor oscuro; "El poeta pide a su amor que le escriba"; textual history.

Recepción: 9 de octubre de 2017; aceptación: 12 de marzo de 2018.

D.R. ( ) 2019. Nueva Revista de Filología Hispánica Licencia Creative Commons Attribution-NonCommercial (CC BY-NC) 4.0 International 
"El poeta pide a su amor que le escriba" fue el soneto póstumo de Federico García Lorca que se publicó en fecha más temprana. De hecho, de los once sonetos que integran la serie de Sonetos del amor oscuro, tan sólo éste y el "Soneto de la dulce queja" se dieron a conocer antes de 1980, mientras que otros seis siguieron inéditos hasta los años ochenta ${ }^{1}$. Curiosamente, varias ediciones posteriores siguieron presentando este soneto como inédito, tal vez por desconocimiento de la primera.

La primera edición conocida del poema aparece en el número 35 de la revista Pan de Bogotá (diciembre, 1939, p. 39), donde figura con el título "El poeta pide a su amor que le escriba". Va precedido del artículo de Manuela Manzanares: "Un soneto inédito de Federico García Lorca” (pp. 35-38).

Vuelve a publicarse en la Revista Hispánica Moderna, números 3/4, julio-octubre, 1940, bajo el epígrafe: "Textos y documentos I. Federico García Lorca: obras inéditas" (pp. 307-314). Aparece en la sección "Poesías inéditas" con el título "El poeta pide a su amor que le escriba” (p. 312). El soneto se publica junto a otros tres poemas que no habían sido incluidos en ninguna colección: la décima sin título que arranca "Norma de ayer encontrada...", una "Canción de cuna para Mercedes muerta" y el soneto "A Mercedes en su vuelo". Estas cuatro composiciones "inéditas" acompañan la edición princeps de Diván del Tamarit, además de algunos de sus poemas que habían sido publicados como poesías póstumas en las Obras completas de Losada. Se incluye también un ensayo dramático juvenil y una carta.

Guillermo de Torre publicó el soneto en la segunda edición de las Obras completas de Federico García Lorca, volumen 6: Así que pasen cinco años. Poemas póstumos (1940, p. 185), con el título "El poeta exige a su amor que le escriba". La fecha del colofón es del 23 de diciembre de 1940. En la "Indicación de fuentes", De Torre menciona haberlo tomado de El Universal de México (23 de febrero de 1940) y añade que la edición habría sido de Manuela Manzanares. Sin embargo, no se ha podido encontrar la citada publicación, ni en la fecha señalada, ni en fechas anteriores o posteriores.

Se edita nuevamente por el Hispanic Institute in the United States como "El poeta pide a su amor que le escriba", en Federico García Lorca (1899-1936). Vida y obra. Bibliografía. Antología. Obras inéditas. Música popular (1941, p. 106). Se trata de una reimpresión exacta, en forma de libro, del número monográfico de la Revista Hispánica Moderna.

Una nueva versión se publica en Corcel (Valencia), número 2 (diciembre 1942-enero 1943, p. 17), con el título "El poeta se queja de que su amor no le escriba".

1 Inéditos hasta la edición no venal en 1983: "Soneto de la guirnalda de rosas"; "Llagas de amor"; "El poeta habla por teléfono"; "[iAy, voz secreta del amor oscuro!]”; "El amor duerme en el pecho del poeta" y "Noche del amor insomne". 
Una sexta impresión titulada "El poeta pide a su amor que le escriba" se encuentra en Nuevo Mundo (Medellín), número 2 (junio 1943, p. 24).

El soneto figura como "El poeta pide a su amor que le escriba", en Federico García Lorca, Obras completas, volumen 6: Asi que pasen cinco años. Diván del Tamarit. Odas. Poemas póstumos, edición de Guillermo de Torre, tercera edición (1943, p. 193). La fecha del colofón es del 23 de octubre de 1943.

Con el mismo título anterior se edita en Federico García Lorca, Antología poética, edición de Rafael Alberti y Guillermo de Torre (1943, pp. 200-201).

La novena edición del poema lleva el título "El poeta exige a su amor que le escriba", en Los mejores sonetos de la lengua española, edición de Rodrigo Castiella (1944, p. 144).

En la primera edición de Aguilar de las Obras completas de Lorca, con recopilación y notas de Arturo del Hoyo, aparece el soneto en la sección de "Poemas sueltos", con el título "El poeta pide a su amor que le escriba" (1954, pp. 543-544).

La edición de Mario Hernández de Sonetos del amor oscuro, con prólogo de Jorge Guillén y aguafuertes de M. Rodríguez-Acosta Calströn (1980), da a conocer un manuscrito sin fecha que se encuentra en la Fundación García Lorca, cuyo título es "Soneto de la carta". Lo acompañan otros tres sonetos hasta entonces inéditos: "Soneto gongorino en que el poeta manda a su amor una paloma", "El poeta pregunta a su amor por la «Ciudad Encantada» de Cuenca" y "El poeta dice la verdad".

En el libro de Federico García Lorca, Diván del Tamarit. Llanto por Ignacio Sánchez Mejías. Sonetos, edición, introducción y notas de Mario Hernández (1981, p. 142), el poema se identifica con el título "El poeta pide a su amor que le escriba".

En noviembre de 1983 aparece una edición no autorizada, de 250 ejemplares numerados, de once sonetos con el título Sonetos del amor oscuro. Según cuenta Mario Hernández, quien fuera uno de los afortunados receptores, la anonimia de la edición es absoluta: carece de nombre de autor, de editor y de impresor; es más, se suprimen los nombres de Aleixandre y Neruda como autores de sendos fragmentos en prosa, alusivos a los sonetos, que anteceden a la edición. Incluso, el nombre de "Federico", que aparece en el texto aleixandrino, es sustituido por unos puntos suspensivos ${ }^{2}$. En enero de 1984, el órgano de Radio Televisión Española, la revista Tele-Radio, hizo una copia pirata del pirata fascículo (Montesinos 1984, p. 57).

${ }^{2}$ Hoy se sabe que la publicación fue hecha a partir de unas fotocopias del hispanista André Belamich, bajo la responsabilidad del profesor Víctor Infantes, y que la edición se tiró en una imprenta de Ocaña (Toledo). 
Queriendo subsanar los numerosos errores que se habían colado en la edición clandestina (no venal, aparecida en noviembre de 1983), la familia se vio instada a permitir la publicación de los sonetos. La nueva edición, autorizada, se llevó a cabo el 17 de marzo de 1984 en el "Sábado cultural" del diario $A B C$ (Madrid), un pliego de dieciséis páginas acompañado por otro central de veinte. Allí, por expreso deseo de los herederos, los poemas se publicaron bajo el título de Sonetos; no obstante, en la portada de ese número de $A B C$, el periódico, bajo su exclusiva responsabilidad, anunció la publicación de unos Sonetos de amor.

El conjunto poemático va acompañado de un artículo introductorio de Miguel García-Posada (pp. 43-44) y de otros a cargo de Fernández-Montesinos (p. 57), Francisco Giner de los Ríos (p. 59) y Lázaro Carreter (p. 3), mientras que Luis María Ansón, director del periódico, se ocupó de escribir el editorial (p. 11). Además, en las páginas de huecograbado, se nos ofrece un álbum fotográfico del poeta. La esmerada edición se completa con una sucinta biografía (p. 58) y una bibliografía sobre Federico García Lorca y su obra (p. 62).

Era la primera vez que aparecían los once sonetos, oficialmente, juntos y ordenados. La edición fue encomendada a Miguel GarcíaPosada, quien la llevó a cabo basándose en los manuscritos del poeta y presentó los poemas en el orden sugerido por las cuartillas dobles del Hotel Victoria utilizadas por Lorca. En esta ocasión, por lo tanto, se adopta el título que figura en el borrador que se conserva: "Soneto de la carta”. Sin embargo, en esta publicación, una nota al texto aclara: "En los archivos de la familia García Lorca se conserva una copia en limpio de este soneto, de mano desconocida, con el título de «El poeta pide a su amor que le escriba»" (1984, p. 48).

Como vemos, en la transmisión del texto figuran cuatro títulos diferentes para un mismo soneto: "El poeta pide a su amor que le escriba"; "El poeta exige a su amor que le escriba"; "Soneto de la carta" y "El poeta se queja de que su amor no le escriba". Y sólo se conocen dos textos base, ambos conservados en el archivo de la Fundación García Lorca.

El primero de ellos, con el título "Soneto de la carta", forma parte del borrador de diez de los sonetos de la serie amorosa, escritos en cuartillas dobles, de papel de hilo para cartas, con membrete del Hotel Victoria de Valencia. Está escrito sobre la tercera cuartilla junto al "Soneto de la dulce queja" y "Llagas de amor". La procedencia de esta copia está suficientemente atestiguada; también existe un relativo consenso sobre la fecha en la que fue escrita ${ }^{3}$. No ocurre lo mismo respecto al segundo.

${ }^{3}$ Federico García Lorca estuvo en esta ciudad, con la compañía de Margarita Xirgu, en la primera quincena de 1935. Hay unanimidad entre los críticos en señalar que el manuscrito data de esa fecha. 
El segundo texto es un apógrafo que lleva por título "El poeta pide a su amor que le escriba". Se trata de una copia en limpio "de mano desconocida” que, según Miguel García-Posada (1996, p. 967), había servido para que Francisco García Lorca y Ángel del Río establecieran la versión del poema publicado en la edición princeps del Diván del Tamarit. Al dorso de la cuartilla, hay dos anotaciones con letra claramente reconocible como del hermano del poeta. Según Mario Hernández, rezan así: "Procurar establecer contacto / con la Internacional / Adr. Polak" y "F. S. de V. / 31 bis Bd. Clemençeau".

Es precisamente este apógrafo el que ha suscitado diferentes hipótesis sobre su procedencia. Entre ellas encontramos la explicación que da Mario Hernández, en cuya reconstrucción del proceso de lecturas y transmisión de los sonetos en vida del autor (1984, pp. 193-228) se hace eco de esta copia, a la que ya se había referido Miguel GarcíaPosada en la edición de los sonetos en el periódico $A B C$ (1984, p. 48).

Según Mario Hernández, se trata de una copia realizada a partir de un autógrafo que Federico García Lorca habría regalado y que, a la muerte del poeta, el copista desconocido debió entregar a Francisco García Lorca en París durante los años de la Guerra Civil. Y añade: "prueba de ello es que Francisco García Lorca editara este texto, conocedor de su procedencia. No ha de preferirse, por consiguiente, el título del borrador" (1984, p. 213).

Intentaré ahora desvelar los errores que a lo largo de la publicación de este soneto se han perpetuado. Mi primera discrepancia se refiere a las anotaciones que se encuentran en el reverso del apógrafo, pues, dada la antigüedad del papel y la pérdida de intensidad de la tinta negra, es difícil ver con claridad lo estampado en el manuscrito. De hecho, Andrew A. Anderson (1997, p.123) señala que las letras transcritas por Mario Hernández como "Adr." son difíciles de descifrar debido a la falta de claridad del manuscrito.

Por mi parte, tengo fundadas razones para pensar que las letras capitales que Mario Hernández ha transcrito como "F. S. de V." corresponden a "F. L. de V.", iniciales que identifican la "mano desconocida" del copista: Fernández López de Valdemoro.

Pero ¿quién era Fernández López de Valdemoro? Carlos, que así era su nombre, nació en Madrid en 1912 y fue uno de los miles de republicanos españoles que se vieron obligados a abandonar España tras el golpe de Estado a la República. Marchó a México, donde encontraría su destino definitivo y moriría, como mexicano, en 1990. Carlos, que había experimentado diferentes vocaciones antes de salir de España (la pintura, los toros, la poesía) y transitado por diversos oficios tras su llegada a México (comerciante, traductor), pronto, en noviembre de 1941, y de manera casual, llega a la radio, donde adoptaría el seudónimo de José Alameda. Desde sus inicios hasta su muerte, el periodismo en sus tres vertientes fue su profesión. Se puede 
considerar que, en el amplio campo de la difusión, José Alameda es el prototipo del periodista hecho en México, ya que fue uno de los primeros exiliados en llegar a la radio, donde haría fortuna su aforismo "el toreo no es graciosa huida, sino apasionada entrega"; vivió los inicios de la televisión mexicana, y sus artículos, crónicas, entrevistas, etc., eran habituales en la prensa.

Además de periodista prolífico, cultivó el ensayo de temática variada y la poesía. No obstante, Carlos Fernández López de Valdemoro (José Alameda) es recordado, valorado y admirado, fundamentalmente, por los aficionados a la tauromaquia, para quienes fue el más importante de los cronistas del mundo taurino de su tiempo; con este género, además, se granjeó el favor del público desde un principio, por su forma, tan diferente de la habitual, de presentar a los personajes, sus dotes literarias y la naturalidad de su discurso. $\mathrm{Su}$ relevancia en el ámbito de los toros y de la comunicación le proporcionó un medio de vida y una gran popularidad, pero al mismo tiempo esta labor impidió que se le reconociera como ensayista ${ }^{4} \mathrm{y}$, sobre todo, como el gran poeta que fue ${ }^{5}$.

Y pese a la relevancia que consiguió profesionalmente y de su proyección como personaje público, su labor literaria no ha recibido atención crítica alguna, e inexplicablemente, ha quedado apartado de los círculos literarios; la bibliografía sobre él es muy escasa y las únicas alusiones a su persona y ejercicio literario suelen apuntar a generalidades, repletas a menudo de errores, o se distinguen por su vaguedad ${ }^{6}$.

Antes de su llegada a México como exiliado político en 1940, en los años treinta, Carlos ${ }^{7}$ era estudiante de derecho de la Universidad Central de Madrid, un joven inquieto intelectualmente y muy interesado en los movimientos de vanguardia que se estaban produciendo en esos años en literatura, pintura y tauromaquia, tres grandes pasiones que le acompañarían durante toda su vida.

Estos intereses lo llevaron a relacionarse con los integrantes de la generación del 27, principalmente con Federico García Lorca, al que

${ }^{4}$ Algunos de los títulos de su obra en prosa son: El toreo, arte católico (1953) y Disposición a la muerte (1953); Ensayos sobre estética (1974); Los heterodoxos del toreo (1979); Retrato inconcluso. Memorias (1982a); El hilo del toreo (1989).

${ }^{5}$ Entre su obra poética se encuentran títulos como Seguro azar del toreo; Sonetos y Parasonetos; Perro que nunca vuelve, Oda a España y seis poemas al Valle de México, y Ejercicios decimales.

${ }^{6}$ La autora de este artículo leyó en septiembre de 2017, en la Universidad de Sevilla, la tesis doctoral cuyo título es José Alameda y el exilio republicano en México, que abarca la biografía, la obra poética, ensayística y periodística de José Alameda.

7 A lo largo de este estudio lo llamaré por su verdadero nombre, "Carlos", ya que los hechos que se relatan son anteriores a 1941, fecha en la que adoptó y comenzó a utilizar el seudónimo de "José Alameda". 
conoció en la primavera de 1931. Puesto que Carlos frecuentaba los ambientes culturales de Madrid, coincidió en repetidas ocasiones y en diferentes circunstancias con el poeta granadino, con quien compartía amigos y conocidos. Poco a poco, la amistad entre ellos, basada en afinidades espirituales, se fue consolidando, sobre todo desde que Federico observó que Carlos conocía su obra en profundidad y la llevaba "tan en la palma de la memoria, que podía sorprender relaciones imprevistas entre los puntos más recónditos de ella” (Alameda 1982, p. 68).

Sabido es que Federico García Lorca buscaba más al oyente que al lector, y además de dar a conocer su obra en tertulias, procuraba leerles a sus amigos cuanto escribía. La primera vez que García Lorca habló a Carlos sobre los Sonetos del amor oscuro fue una tarde en su casa de la calle Alcalá de Madrid. Los guardaba en el cajón de la mesa de trabajo de su dormitorio, el cual se encontraba al fondo del piso que ocupaba con su familia:

Pero Federico, que me había leído el Llanto por Ignacio Sánchez Mejias cuando iba a su mitad y Yerma cuando aún no pasaba del primer acto, se negaba a decirme todos los sonetos o a repetirme los que ya había escuchado. Y, como para distraer mi ruego, me hablaba de la intención de estos poemas, no de cada uno de ellos, sino del libro como un todo, pues consideraba que tenía una gran unidad, semejante en lo suyo al Romancero Gitano (Alameda 1982, p. 65).

El hecho de que el sonetario quedase sin publicar a la muerte del poeta granadino, sin duda ha ocasionado numerosas incógnitas acerca del número total de sonetos escritos, así como del título que el poeta pensaba darles. Desgraciadamente, Carlos no dice el número de poemas que integraban el libro, pero sí nos confirma la unidad del poemario. En el mismo sentido va el testimonio oral de Joaquín Romero Murube, recogido por García-Posada en García Lorca (1979, p. 321), según el cual el poeta granadino pretendía escribir un libro de sonetos amorosos como el de Shakespeare. El recuerdo data de abril de 1935. Luis Rosales, en sus declaraciones a Jean-Luis Schönberg en los años cincuenta, o a Miguel García-Posada en los ochenta, siempre habló de la existencia de treinta o treinta y cinco poemas cuyo título sería Jardín de los sonetos. Rafael Martínez Nadal escribe sobre los Sonetos del amor oscuro: "recuerdo haberle oído recitar unos ocho o diez..., pero ignoro cuántos dejaría escritos” (1970, p. 258). Mario Hernández (1984, p. 194) apunta que seguramente el título Sonetos del amor oscuro fue uno de los primeros títulos pensados por Federico García Lorca para su libro.

El citado título fue divulgado a partir de la conocida evocación que publicara Vicente Aleixandre tras el asesinato del poeta: 
Recordaré siempre la lectura que me hizo, tiempo antes de partir para Granada, de su última obra lírica, que no habíamos de ver terminada. Me leía sus Sonetos de amor oscuro, prodigio de pasión, de entusiasmo, de felicidad, de tormento, puro y ardiente monumento al amor, en que la primera materia es ya la carne, el corazón, el alma del poeta en trance de destrucción.

Este texto, "Federico", fue recogido en Hora de España, 7 (julio de 1937, pp. 43-45), y en Homenaje al poeta García Lorca contra su muerte (1937, pp. 27-30); también fue incluido por Arturo del Hoyo como "Epílogo" a las Obras completas de Lorca (1954 y ediciones posteriores).

Es cierto que, al hablar en público de esta serie, García Lorca siempre empleó el escueto título de Sonetos; además, no se conoce ningún manuscrito poético ni carta suya que consignase el título. Sin embargo, en privado, con sus amigos, Sonetos del amor oscuro fue el título elegido por Lorca. Así lo señala Carlos Fernández López de Valdemoro, y así lo señalaron Vicente Aleixandre y Luis Cernuda, entre otros.

Desde que esta serie de sonetos se publicara, se han ido agregando connotaciones al sintagma "amor oscuro" que constituyen una intromisión en la vida íntima del poeta y que, en ocasiones, han empañado la calidad lírica de la obra. Por eso, considero importante recoger literalmente las palabras de Carlos sobre el que creía "un libro perdido":

Lejos de "folklorismos" convencionales, Federico refleja lo esencial de su tierra. Y es allí donde encuentra el "amor oscuro". Un amor sin referencia explícita a la amada o al amado. Porque es el Amor y no lo amado, quien asume el papel de protagonista. En ninguna creación directa, genuina, del pueblo del sur de España, el amor toma desinencia ni femenina, ni masculina...

Amor oscuro -pero resplandeciente- que tapa y oscurece a lo amado, sin nombrarlo nunca.

Es una actitud que podríamos llamar "antimística”. En los místicos, el Amado está en primer término, como un protagonista estelar-¿un Jesucristo superestrella? En cambio, en el canto del sur, el Amado está siempre sin nombre y sin sexo, aludido o sobreentendido, oculto.

De ahí partía Federico, sin conservar por ello acento alguno de "coplero", sino dando al soneto todos sus mármoles, propicios al amor puro, al amor sin "concreciones novelísticas".

Sucede, por lo demás, que el amor siempre es oscuro. Aun en el que pueda aparecer más claro, uno de esos amores de paisaje transparente y aire azul, se produce de pronto, sin saber cuándo, un reacomodo geológico, allá abajo, y hay una capa de tierra o de piedra que oprime y rompe un vaso, para que la corriente subterránea de agua o de sangre hiele o nuble el corazón (Alameda 1982, pp. 67-68). 
No siendo el objeto de este artículo adentrarme en el sentido y análisis de los Sonetos del amor oscuro, sí considero que cabe una nota parentética acerca de la opinión que sobre ellos da un conocedor de primera mano, como lo fue Carlos Fernández López de Valdemoro. Carlos aleja de pintoresquismo y folclorismo los sonetos de Lorca ${ }^{8}$, situando su origen en lo "esencial de su tierra", a lo que yo añadiría que dichos sonetos son deudores de toda una tradición literaria sobre el amor. En su interpretación, Carlos se aleja de una lectura apegada al biografismo del poeta granadino (como sí hicieran tempranamente Schönberg y sus seguidores, y, más recientemente, Ian Gibson, entre otros), remarcando que este amor "no toma desinencia ni femenina, ni masculina". Visión que comparto, pues los Sonetos del amor oscuro son la expresión de un "amor pasión", un amor oscuro en el sentido de misterioso, que ciega, turba la razón y ofusca el entendimiento, que enajena, sorprende y aturde, un sentimiento en el que lo esencial es precisamente el Amor con mayúscula y no el objeto de esta pasión, sea éste "masculino o femenino". Efectivamente, como analiza Matas Caballero (1999-2000, pp. 361-386), es evidente que Lorca acude a técnicas ya utilizadas por los grandes poetas místicos; su lenguaje, basado en el símbolo, la metáfora y atravesado por el oxímoron y la antítesis, lo acercan al léxico de los poetas místicos, fundamentalmente a san Juan de la Cruz y a la tradición literaria por él asumida; pero las alusiones, los ecos de la poesía mística, que los críticos encuentran en sus sonetos, considero que pertenecen a la atmósfera del tema, son elementos de los poemas, que no determinan su intención, por lo que, según mi opinión, Lorca no puede ser considerado un poeta místico.

En los sonetos de García Lorca se advierten préstamos que tienen historia y resonancia milenarias, una rica intertextualidad en la que se trenza lo culto y lo popular; pero el tratamiento que reciben es singular, original y único en sus manos, reelabora la tradición recibida y la acomoda a sus necesidades expresivas.

Continúo con la reproducción de lo escrito por Carlos, ya que estos vívidos recuerdos no sólo nos dan la medida de la relación que unía a los dos amigos, sino que prueban la reserva del poeta granadino, por un lado, y la lealtad de Carlos, por otro. Federico, prudente al no decir, al no hablar de sus sentimientos amorosos; Carlos, leal al no contar, al no descubrir la intimidad de su amigo. Ambos quedan así vinculados por la discreción compartida:

Se había acostumbrado Federico a que yo lo entretuviera... de modo que, si sufría alguna congoja íntima y se sentía solo, o en esa soledad en compañía que son ciertas tertulias literarias, se comunicaba conmi-

${ }^{8}$ Propósito semejante persiguió el autor en su estudio sobre "El toro en la obra de Federico García Lorca". 
go y nos íbamos a dar un paseo por los alrededores de Madrid en un coche que alquilaba, o a meternos por las barriadas, perdidos en calles o en pequeños cafés. Pero nunca me hablaba de lo que traía por dentro. No buscaba confidente. Al contrario, pues lo que quería no era recordar, sino precisamente olvidar. De mi desinteresado entusiasmo juvenil, aguardaba el despertar de aquellos temas literarios que, por ser muy suyos, lo distraían y lo consolaban. Era yo su analgésico amigo. Y ello conscientemente, pues incluso sabía quién era la persona de sus cuitas, como lo sabíamos algunos pocos amigos suyos. Pero me guardaba de nombrarla o aludirla. Estaba allí también la ley del amor oscuro, ley que, viniendo de la tierra, pasaba a la vida del poeta y de allí, irremediablemente, a su poesía (1982, p. 69).

Una tarde de junio de 1936, después de un largo paseo, ya de vuelta al centro, se detuvieron en el café La Rotonda, cerca de la casa de Federico. Por aquellos días, advierte Carlos que "Federico tenía algún grave dolor, alguna zozobra íntima. Llamémosle así al amor". Fue allí donde Carlos le habló, como tantas veces, de los sonetos, y, sin más, empezó a decírselos. Recuerda que se pasaron horas volviendo sobre algunos de ellos:

Hasta que saqué lápiz y papel y le pedí que me dictara los dos que yo había preferido. Lo hizo con uno, "El poeta pide a su amor que le escriba”. Cuando llegamos al otro, Federico, como si de pronto despertara, se arrepintió.

La otra composición era "El poeta habla con su amor desde la cabina del teléfono”, composición que Carlos creía perdida cuando publicó estos recuerdos en 1982, ya que el soneto se imprimió por vez primera en la edición no venal de Sonetos del amor oscuro de 1983.

Tras la sacudida del golpe de Estado a la República, en julio de 1936, la noticia concreta del asesinato de Federico García Lorca un mes después sonó como un trallazo que iba precisando las dimensiones de la tragedia. Carlos se incorpora al Servicio Español de información a las órdenes del poeta Juan José Domenchina. Al poco tiempo, debido a una afección pulmonar, es ingresado en el sanatorio Puig de Olena (Barcelona), donde permanece entre mayo del 37 y marzo del 38. A finales de 1937, desde el sanatorio escribió a Francisco García Lorca, al que había conocido por Federico, pero también por Eduardo Ugarte durante los preparativos del teatro universitario La Barra$c a$. Por entonces, Francisco era secretario de la Embajada de España en Bruselas, la cual estaba al mando del catedrático y famoso penalista Mariano Ruiz-Funes. Por esta carta de Carlos puedo confirmar que fue en Bruselas donde Francisco García Lorca recibió el apógrafo, no en París, como se ha venido diciendo. La carta también aclara que la copia no fue un mero regalo del amigo, sino un texto que 
Carlos transcribió siguiendo el dictado directo del poeta. Después de contar cómo había obtenido el soneto y de explicar que pertenecía al poemario perdido, Carlos mandó a Francisco García Lorca su transcripción del soneto ${ }^{9}$ :

Amor de mis entrañas, viva muerte, en vano espero tu palabra escrita y pienso, con la flor que se marchita, que si vivo sin mí quiero perderte.

El aire es inmortal. La piedra inerte ni conoce la sombra ni la evita. Corazón interior no necesita la miel helada que la luna vierte.

Pero yo te sufrí. Rasgué mis venas, tigre y paloma, sobre tu cintura en duelo de mordiscos y azucenas.

Llena, pues, de palabras mi locura o déjame vivir en mi serena noche del alma para siempre oscura ${ }^{10}$.

\section{Según nos cuenta Carlos,}

Paco conocía este soneto, como los restantes del libro, aunque no tuviera su texto, y lo reconoció de inmediato, según me lo dijo en su respuesta y más tarde en persona, cuando, repuesto yo de mi dolencia, alcancé a trabajar un corto tiempo en la cancillería de la propia embajada española en Bruselas, con el maestro Ruiz Funes (1982, p. 70).

Desafortunadamente, no tenemos la carta dirigida a Francisco ni la respuesta de éste, pero sí la transcripción del soneto, cuya letra he podido cotejar con otros escritos de Carlos, entre ellos unas cartas manuscritas dirigidas a Federico en 1935, publicadas en la revista Cuadernos Hispanoamericanos (Coleto 2015, pp. 79-92).

Compruebo que el soneto publicado en 1940 en la Revista Hispánica Moderna, una vez subsanados los descuidos a los que hacía referencia en la nota 10, es exactamente igual al enviado por Carlos Fernández López de Valdemoro a Francisco García Lorca.

9 Mi agradecimiento a La Fundación García Lorca, que amablemente ha puesto a mi disposición el apógrafo.

${ }^{10}$ He añadido, por considerarlo un descuido de la escritura, y no variantes respecto a otras ediciones, el punto final de las estrofas 1,2 y 3 -de hecho, los versos siguientes a estas estrofas comienzan con la correspondiente letra capital-, y corregido la falta de tilde en "dejame" del verso 13. 
La misma similitud presenta el publicado en 1941 por el Hispanic Institute in the United States, puesto que se trata de una reimpresión de $R H M$. Volverá a reimprimirse exactamente igual en la Antología poética (1943). Por su parte, Miguel García-Posada declara seguir el texto de la neoyorquina $R H M$ en la edición del soneto en Akal (1984, pp. 763 y 404), así como en las Obras completas de Federico García Lorca (1996, p. 629). Y, en general, es esta temprana edición la que se ha considerado como texto base autorizado. Se reproduce el mismo texto en la edición Aguilar (1954), aunque en este caso se omite poner el punto final en la cuarta estrofa.

El texto del poema dado a conocer en Pan (1939), en cambio, aunque lleva el mismo título que las ediciones anteriormente citadas, presenta variantes significativas respecto a ellos. Así, cambia la coma al final del v. 1 por dos puntos; suprime las comas del v. 3; añade coma intermedia en los vv. 4 y 7 ; cambia el punto intermedio del v. 9 por una coma; suprime la coma intermedia del v. 10; añade una coma al final del v. 12. También añade una tilde innecesaria en "Lléna", v. 12. Las variantes señaladas son suficientes para consignar la distinta procedencia de la copia utilizada para esta edición. A la misma conclusión llega Anderson, quien, después de investigar la posibilidad de que la versión publicada en Pan proceda del apógrafo objeto de mi investigación, hace la siguiente observación: "A total of seven differences in punctuation; of these, the colon in v. 1 and the comma in v. 9 are particularly significant and suggest strongly that Pan derives from a different copy or possibly even from a different autograph" (1989, p. 117).

Por lo demás, compruebo que el texto del soneto publicado en Nuevo Mundo es reproducción exacta de Pan, salvo que introduce alguna errata: "es $m i$ inmortal" en el v. 5, y "ser $a$ na" en el v. 13; incluso mantiene la tilde innecesaria de "Lléna" del v. 12. En la segunda edición de Losada (1940), el título del poema reemplaza "pide" con "exige" y elimina la tilde innecesaria de "Lléna"11; pero, en todo lo demás, es fiel a Pan. En su tercera edición (1943), se reproduce el mismo texto, pero se adopta el título "El poeta pide a su amor que le escriba". Pienso que la versión publicada en Los mejores sonetos de la lengua española (1944) está basada en la segunda edición de Losada, ya que sólo ella mantiene "exige" en el título; también conserva la puntuación, excepto que añade una coma en el v. 2 y elimina la coma intermedia del v. 4. El texto del poema que se dio a conocer en Corcel (1942-43) es la única versión publicada con el título "El poeta se queja de que su amor no le escriba". No obstante, presenta una puntuación semejante a la de Pan, excepto la coma que se agrega al

11 A partir de aquí, esta corrección en la ortografía se adoptará en las siguientes versiones que provienen de Pan. 
final del v. 10; la supresión de la coma final del v. 12; y el cambio del posesivo " $m i$ serena" por el artículo "la serena" en el verso 13. La edición del poema que ofrece Mario Hernández (1981) sigue la de Pan: los dos puntos al final del v. 1; la falta de la coma intermedia del v. 3; la coma intermedia que se agrega en los vv. 4, 7 y 9 ; y la coma intermedia suprimida del v. 10. La única diferencia es que Hernández no agrega coma al final del v. 12.

Finalmente, aunque Anderson (1989, p. 115) proclamó que el poema nunca había sido publicado con el título "Soneto de la carta”, Mario Hernández lo dio a conocer con ese título en su edición de 1980, como también García-Posada en la edición de $A B C$ (1984, p. 48). A la luz de estos datos, parece claro que, aparte del manuscrito y del apógrafo que posee la Fundación García Lorca, existe una tercera copia que ha dado lugar a la versión publicada por Pan y sus seguidores.

Me sorprende que Francisco García Lorca, habiendo dado por bueno el apógrafo que recibiera de Carlos Fernández López de Valdemoro y conociendo todos los datos relativos a él, no lo mencionara cuando, en colaboración con Ángel del Río, fijó el texto del poema para la edición de $R H M$, basándose para ello justamente en dicha copia. El silencio mantenido por Francisco García Lorca sobre la persona que le proporcionó el soneto, así como su decisión de no respetar el título del poemario al que pertenecía han contribuido a crear incógnitas y a desencadenar las hipótesis más dispares.

Debido a ello, nos encontramos, por ejemplo, que la primera edición en Aguilar, basada en RHM, todavía sitúa el soneto en la sección de "Poemas sueltos" (1954, pp. 543-544), sin hacer ninguna referencia al libro del que procede. Además, en las notas al texto de esta edición, el editor se pregunta si "El poeta pide a su amor que le escriba" es uno de los Sonetos del amor oscuro (p. 1628). Le surge la misma duda respecto a la composición "[Largo espectro de plata conmovida...]". Evidentemente, este soneto no pertenece a Sonetos del amor oscuro. La propia edición suministra la prueba al incluirlo dos veces en diferentes secciones: figura en "Poemas sueltos", como ya se ha dicho, pero también, mucho antes, en el libro Canciones (escrito entre 1921 y 1924), sitio que verdaderamente le corresponde. Como señala Carlos, "por aquella fecha... Federico no había ni siquiera intuido los Sonetos del amor oscuro" (Alameda 1982, p. 71).

¿Por qué Francisco García Lorca no dijo desde un principio que el soneto pertenecía a la serie Sonetos del amor oscuro? No creo que haya una sola respuesta a esta pregunta, sino que un cúmulo de razones vino a aunarse. Señalaría entre las mencionadas causas la dificultad que entrañaba recoger y ordenar la obra inédita a la muerte del poeta; de igual forma pesaba el deseo de la familia de que su edición estuviese preparada con el rigor y la seriedad filológica que la obra 
merecía. Recordemos que no se sabía con certeza cuántos sonetos eran parte integrante del libro, ni si aparecerían nuevas versiones de los sonetos ya conocidos por la familia -Lorca, además de dar lecturas públicas y privadas, solía regalar sus poemas a los amigos. Todo esto contribuyó sobremanera a la dificultad de la tarea emprendida por la familia.

A los problemas textuales planteados por la obra, hay que sumar los derivados de la especulación acerca de la vida íntima del poeta, sobre todo a partir de la publicación en 1956 del libro de Jean-Louis Schönberg, en el que el crítico hacía una interpretación homosexual de la obra del poeta granadino. A este respecto escribe García-Posada en "Un monumento al amor":

Es de esperar... que la publicación, con las debidas garantías jurídicas y textuales, de "todos" los sonetos de amor hasta ahora conocidos de Federico García Lorca contribuya a arrumbar ese muro de equívocos y maledicencias que, desde hace ya algunos años, se ha levantado en torno a la figura del poeta. La consigna del lamentable monsieur Schonberg, un crítico de tercera fila, ha sido bien atendida, y una serie de advenedizos irresponsables se han lanzado sobre la obra y la memoria de Lorca (1984, pp. 43-44).

Creo que estas razones desempeñaron un papel determinante, sobre todo a la hora en que la familia decidió publicarlos e identificarlos de esta forma. Todo ello ha contribuido a que hayamos tenido que esperar tanto tiempo para ver "El poeta pide a su amor que le escriba" restituido al libro para el que fue concebido: Sonetos del amor oscuro.

\section{REFERENGIAS}

Alameda, José 1953. El toreo, arte católico. Disposición a la muerte, Publicaciones del Casino Español de México, México.

Alameda, José 1974. Seis poemas al Valle de México y Ensayos sobre estética de Velasco a Cuevas y de Goya hasta Picasso y Dalí, Costa-Amic, México.

Alameda, José 1979. Los heterodoxos del toreo, Grijalbo, México.

Alameda, José 1980. "El toro en la obra de Federico García Lorca", en La pantorrilla de Florinda y el origen bélico del toreo, Grijalbo, México, pp. 79-106.

Alameda, José 1982. 4 libros de poesía. I Sonetos y parasonetos. II Perro que nunca vuelve. III Oda a España y Seis poemas al Valle de México. IV Ejercicios decimales. Apéndice I y II, Océano, México.

Alameda, José 1982a. Retrato inconcluso. Memorias, Océano, México.

Alameda, José 1983. Seguro azar del toreo, Salamanca Ediciones, México.

Alameda, José 1989. El hilo del toreo, Espasa Calpe, Madrid.

Aleixandre, Vicente 1937. "Federico", en Homenaje al poeta García Lorca contra su muerte. Ed. Emilio Prados, Ediciones Españolas, Valencia-Barcelona, pp. 27-30.

Aleixandre, Vicente 1937. "Federico", Hora de España, 7 (julio), pp. 43-45. 
Anderson, ANDrew A. 1997. "New light on the textual history of García Lorca's Sonetos del amor oscuro", en Negotiating past and present: Studies in Spanish literature for Javier Herrero. Ed. David Thatcher Gies, Rookwood Press, Virginia, pp. 109-126.

Ansón, Luis María 1984. Editorial “Sonetos de amor”, $A B C$, Sábado Cultural (17 de marzo), Madrid, p. 11.

Castiella, Rodrigo (ed.) 1944. Los mejores sonetos de la lengua española, Editora ZigZag, Santiago de Chile, p. 144. (Serie Celeste, 5 ).

Coleto Camacho, Ana 2015. "Tres cartas inéditas de Carlos dirigidas a Federico García Lorca”, Cuadernos Hispanoamericanos, 778, pp. 79-92.

Coleto Camacho, Ana 2017. José Alameda y el exilio republicano en México, tesis, Universidad de Sevilla, Sevilla.

Fernández-Montesinos, Manuel 1984. “Algunos sonetos de Federico García Lorca: ¿por qué ahora y en $A B C$ ?”, $A B C$, Sábado Cultural (17 de marzo), Madrid, p. 57.

García Lorca, Federico 1940. "Federico García Lorca: obras inéditas", Textos y documentos de Revista Hispánica Moderna, 6, 3/4, University of Pennsylvania Press, pp. 307-314.

García Lorca, Federico 1940a. Obras completas, $2^{\mathrm{a}}$ ed. Ed. Guillermo de Torre, Losada, Buenos Aires.

García Lorca, Federico 1943. Antología poética. Eds. Rafael Alberti y Guillermo de Torre, Pleamar, Buenos Aires.

García Lorca, Federico 1943a. "El poeta se queja de que su amor no le escriba", Corcel, 2 (diciembre 1942-enero 1943), p. 17.

García Lorca, Federico 1943b. Obras completas, $3^{\mathrm{a}}$ ed. Ed. Guillermo de Torre, Losada, Buenos Aires.

García Lorca, Federico 1943c. "El poeta pide a su amor que le escriba", Nuevo Mundo, Medellín, 2 (junio), p. 24.

García Lorca, Federico 1954. Obras completas. Recopilación, cronología, bibliografía y notas de Arturo del Hoyo. Prólogo de Jorge Guillén, epílogo de Vicente Aleixandre, Aguilar, Madrid.

García Lorca, Federico 1980. Sonetos del amor oscuro. Ed. y notas de Mario Hernández. Pról. de Jorge Guillén. Aguafuertes de M. Rodríguez-Acosta Calströn, Maeght, Barcelona.

García Lorca, Federico 1981. Diván del tamarit. Llanto por Ignacio Sánchez Mejías. Sonetos, en Obras de Federico García Lorca, 3. Ed. Mario Hernández, Alianza Editorial, Madrid.

García Lorca, Federico 1982, 1989, 1998. Obras completas II. Poesía. Ed. Miguel García-Posada, Akal, Madrid.

García Lorca, Federico 1984. "Lorca: Sonetos”. Ed. Miguel García-Posada, ABC, Sábado Cultural (17 de marzo), Madrid, pp. 45-56.

García Lorca, Federico 1996. Obras completas. I. Poesía. Ed. Miguel García-Posada, Galaxia Gutenberg-Círculo de Lectores, Barcelona.

García-Posada, Miguel 1979. García Lorca, Edaf, Madrid.

García-Posada, Miguel 1984. "Un monumento al amor", $A B C$, Sábado Cultural (17 de marzo), Madrid, pp. 43-44.

Giner de los Ríos, Francisco 1984. "Lorca o el asombro”, $A B C$, Sábado Cultural (17 de marzo), Madrid, p. 59.

Hernández, Mario 1984. "Jardín deshecho: los «Sonetos» de García Lorca”, El Crotalón. Anuario de Filología Española, 1, pp. 193-228.

Lázaro Carreter, Fernando 1984. "Poesía de García Lorca recuperada”, $A B C$, Sábado Cultural (17 de marzo), Madrid, p. 3.

Manzanares, Manuela 1939. "Un soneto inédito de Federico García Lorca”, Pan, 35 (diciembre), Bogotá, pp. 35-39.

Martínez Nadal, Rafael 1970. El público. Amor, teatro y caballos en la obra de Federico García Lorca, The Dolphin Book, Oxford. 
Matas Caballero, Juan 1999-2000. "Federico García Lorca frente a la tradición literaria: voz y eco de San Juan de la Cruz en los Sonetos del amor oscuro", Contextos, 33/36, pp. 361-386.

Río, Ángel del, Sidonia C. Rosenbaum y Federico de Onís 1941. Federico García Lorca (1899-1936), Hispanic Institute in the United States, New York.

Schönberg, Jean-Louis 1956. Federico García Lorca. L'homme-l'oeuvre. Préf. de Jean Cassou, Plon, Paris. 